\title{
Successful school management in contexts with challenges (some lessons from practice)
}

\author{
VICENTE CARRASCO-EMBUENA , CONCEPCIÓN SUÁREZ-LLORCA \\ Department training and special didactic, Faculty of Education, University of Alicante, Spain
}

\begin{abstract}
Carrasco-Embuena V, Suárez-Llorca C. Successful school management in contexts with challenges (some lessons from practice). J. Hum. Sport Exerc. Vol. 5, No. 3, pp. 418-429, 2010. This article reports data and conclusions on a research project, developed in the triennium 2005-08, under the Socrates-Comenius Programme, with the participation of nine European countries: England, Portugal, Holland, Sweden, Finland, Greece, Poland, Ireland and Spain, which principal objectives are geared to characterize the best practices of leadership in Early Childhood Education centres, Primary schools and Secondary schools, located in urban areas with challenges, and to identify the strategies used by their principals, in order to elaborate materials to facilitate the management of education and schools which can be used to train school leaders in any European country. The project includes thirty-six case studies, four from each participating country. Principals' qualities and their strategies are identified and analyzed from the perspectives of the involved sectors (students, parents, teachers and themselves). The research offers emerging and significant topics, strategies and procedures as well as useful materials for education management, which can be of use in training management teams. Key words: LEADERSHIP, MANAGEMENT TEAMS, EDUCATIONAL RESEARCH.
\end{abstract}

Corresponding author. Department training and special didactic, Faculty of Education, University of Alicante, Campus de San Vicente s/n, 03690-Alicante, Spain.

E-mail: vicente.carrasco@ua.es

Submitted for publication July 2010.

Accepted for publication September 2010.

JOURNAL OF HUMAN SPORT \& EXERCISE ISSN 1988-5202

(C) Faculty of Education. University of Alicante

doi:10.4100/jhse.2010.53.12 


\section{INTRODUCTION}

For the last fifty years, at least, leadership has been an object of investigation in different areas, in the context of trade and economic organizations and also in service companies and institutions (education, health, social services...). From the very first investigations, initiated in the last century thirties, until today, the characteristics of the contexts and conditions in which organizations develop have varied radically.

Focusing on the educational field, the progressive increment in the complexity of variables that converge on school organizations is indisputable. This requires further research on leadership that must be enabled and encouraged to tailor its management to the demands of nowadays society, which evolves rapidly and promotes new urgent and even contradictory requirements to schools; requirements that are difficult to satisfy and place school management in a complex scenario, characterized by multiple dilemmas.

Specialized literature has highlighted the importance of leadership as a practice to improve educative institutions, understood not as a personal or characteristic attribute of leaders, but in the sense that Elmore (2006) defends as a 'set of action models, based on a body of knowledge, skills and habits of mind that can be objectively defined, taught and learned'. In the past two decades, different conceptions of leadership have emerged and have been discussed. Among others, Bass (1990) contrasts the perspectives of transactional leadership and transformational leadership. The first is characterized by explaining people's motivations by positive and negative reward mechanisms, considering that social systems work better with a clear chain of command, in which everyone transfers authority to management, and proceed according to what it establishes. On the contrary, transformational leadership focuses on the idea of motivation, as a result of an awareness task; as what drives people conveniently to accomplish a genuine teamwork.

In disagreement with traditional leadership theories, which take satisfaction and knowledge of subordinates as dependent variables, theories of transformational leadership adopt as variables emotional responses, stimulus, and participants' self-esteem, trust and security in leaders, individual values, and their motivation to get involved, beyond what they call 'duty'. On the other hand, unlike those theories that describe leadership in terms of tasks and people-oriented behaviours, new theories conceive it in terms of articulating and focusing visions and missions, creating and safeguarding a positive image in people's minds, implanting challenging expectations for all, showing trust and respect for them and adopting behaviours that reinforce the vision and the mission of the organization (House \& Singh, 1987).

Another key emerging question related to leadership is the idea that, in many cases, it's a temporary and located phenomenon, with a short duration, which produces little widespread improvements, although at the same time it points out that certain managers transcend what we could call a bad management of change, taking one more step and boosting reforms that respond to the denominated 'sustainable leadership', that Hargreaves and Fink (2003) characterize as 'the [leadership] that extends and is durable. It is the shared responsibility which does not improperly exhaust human and financial resources, that is concerned to avoid negative collateral damage in the educational environment and the community. Sustainable leadership has an active commitment with the strengths that influence it, and creates an educational atmosphere of organization of the organizational diversity, promoting the exchange of ideas and good practices in shared learning and development communities'.

To get to this definition, authors start from the context of the natural and human environment of educational institutions and focus their contributions in one of the most important aspects, and often most forgotten, of leadership: sustainability. The target they pursue is a long-term leadership, not immediate, and for every 
school, not only for a few of them. To achieve it, they outline a framework of seven characteristic values of sustainable leadership: a scheme that fits deep learning and effective achievements versus performance superficially appreciated through tests; the duration of long-term impact beyond individual leaderships, with continuity in an efficient management; the influence amplitude, which turns leadership into a shared responsibility; the justice to make sure leaders actions don't damage students, but help finding ways of sharing knowledge and resources with other schools and local communities diversity, which substitutes standardization and monotony by plurality and generates cohesion and new relations; ingenuity, which maintains and renews the leaders' strengths and does not allow them to feel disillusioned; and, finally, conservation, which parts of the most outstanding of the past to build a better future.

We stand conceptually in this perspective and, therefore, our methodological approach adopts an interpretative approximation of school organizations. We conceive schools as places where educative agents relate and interact; they are who really generate daily situations. Our perspective is micro-political, conceiving schools as dynamic realities, complex and changing, characterized by power relations, influence, conflict, diversity of interests and aims, of ideologies and values. All of it gives them the character of unpredictable organizations, vulnerable to external and internal influences, which host a multiplicity of interpersonal relations that must be investigated and considered if we wish to know their real function.

\section{RESEARCH DEVELOPMENT}

The essential claim of this paper is to present the development and results of the Socrates-Comenius Project (Action 2.1), which under the label 'Strategies for Leading Successful Schools in Urban Contexts with Challenges, 2005-2008', is a research promoted by nine European universities and financed by the European Union, which seeks to contribute to the in-service training of management teams of nonuniversity schools.

The main objectives and expectations of this project of R\&D are to identify the most successful strategies that educational leaders use to manage schools in disadvantaged contexts with success, and, later, elaborate transnational formative materials susceptible to be used in managers' training. For this purpose, we have selected thirty-six urban schools of Early Childhood/Primary/Secondary Education, belonging to nine European Union countries which, coordinated by their local universities, have conducted this triennial project of research and development.

The participating universities and countries are England (University of Nottingham, which has coordinated the project), Poland (University of Lodz), Finland (University of Helsinki), Sweden (University of Umea), Portugal (University of Minho-Braga), Greece (Aristotle University, Tesalónica), Ireland (St. Patrick's College, Dublin), Holland (Inholand University) and Spain (University of Alicante). The Spanish schools that have collaborated in the research are the state schools of Early Childhood and Primary Education San Roque and Virgen del Remedio, and the Secondary Education Antonio J. Cavanilles and Virgen del Remedio, all located in Alicante city. On the other hand, Spanish researchers assigned to the project belong to the Department of General and Specific Didactics of the University of Alicante.

The research was methodologically carried out through a sequence that contemplates the following phases: 
a) Selection in each country of two Primary schools and other two Secondary schools, all located in contexts of social and economic disadvantage.

b) Fieldwork with managers and school community members to identify successful school management strategies, and provide evidence of them.

c) Comparison and contrast of the findings in the different countries and elaboration of a document, supervised and evaluated by every participating country.

d) External evaluation of the project by an institution belonging to a non-participating country (Danish School of Education. Denmark)

The implementation of the research has provided the participant schools some opportunities that ought to be highlighted. On the one hand, it has made them start an inquiry job through inter-institutional and transnational cooperation. On the other hand, it has allowed them to know and exchange points of view and experiences with other schools located in different countries, with diverse school cultures. Thirdly, it has given the schools' members the role of key players in the development and configuration of the training materials, which are the last aim of the project. Finally, it has allowed them to assist and participate actively in the Nottingham general meeting in August 2008, which, besides being the conclusion of the project, was intended to promote exchange, final discussion and dissemination of its results among the whole of the participating schools and managers.

The project has been developed in six phases which correspond to the following steps: i) design of the procedures for the selection of schools; ii) harvest of data through common protocols, which had been previously agreed by researchers; iii) analysis of data, according to previously agreed schemes; iv) first elaboration of experimental materials; v) piloting of materials in the different countries, according to agreed strategies, through focus groups with the participation of managers; and, vi) revision, recapitulation, discussion and writing of the final report, including the proposal of materials which were to be diffused in the languages of the participant countries in DVD format.

\section{Selection of schools}

For the school selection, different variables were activated. As for principals, they should have managed their schools for a period of at least five years, taking care that in each country there was a balanced number of principals. Finally, we looked for a positive readiness from them to take part and lead collaborative work groups. As for the school context, criteria they should be schools with important quotas of students from disadvantaged social and economic contexts and with an evident presence of behaviour problems and other associated dysfunctions. This meant to be located in urban areas with important challenges of all kind and respond, in what is related to their students' composition and their social communities, to the representative traits of each country social reality. Besides, the reputation of the schools had to be sufficiently contrasted through indicators such as school inspection reports, information collected from the media, social prestige or results in external evaluations, among other evidence.

Singularly, in connection with the students' class attending and their academic performance, the selection required an improvement in the absenteeism results during the mandate of the actual principals to be perceptible and, on the other hand, an improvement in the levels of achievement was also required, either through the process of external valuation (in countries where systems ad hoc are implanted) or internal valuation (where they're not implanted). Finally, improvements in the index of the students' marginalization as well as in conflict and unsocial behaviours were demanded too. 


\section{Harvest of data}

Techniques and instruments used to collect data have been mainly semi structured and simultaneous interviews with the principals of the selected schools. They have been complemented with focus group work with the diverse collectives in each school (teachers, parents and students), taking into account their characterization as key-informers. They haven't been chosen at random, but their trajectory and experience in their respective schools has been valuated, as their implication in the school boards and parents/students associations or their performance as members of management teams or in charge of responsibility tasks.

Collection was initiated with an extensive semi structured interview with the principals of each school, which covered different aspects:

i) About their biographies, taking note of significant data about their arriving to the school, job they were assigned to, time of leadership work and a summary of their career as principals.

ii) As for their perception of the school, identifying its principal aspects and characteristics, highlighting its strengths and challenges to achieve. They were also asked about their interest in remaining there and, in that case, the reasons why or, alternatively, if they would rather work in other schools with less challenges, the reasons of their election. Besides, they were asked to explain how they faced the school challenges, what support they received in their management task, as well as what factors they considered essential for their school success. Finally, they were asked for evidence and explicit examples that illustrated their assertions.

iii) Relating to the appreciation they had of their own leadership and the evolution of the school in the course of time, describing the role they had played as successful leaders in the school and the strategies they had used in the different management levels of the school.

iv) With reference to the definition of their professional profiles, specifying the values, aspirations or purposes that guided their task, the way their prior experience to their arrival at the school had influenced or not in their activity in it, the perception they had of other hypothetic active leadership actions in the school and the extent to which they interacted with their own leadership role. Finally, they were asked for examples of how their leadership and management strategies had evolved or not along the time they had managed the school.

v) The interview concluded with questions about the characteristics they attributed to principals of similar schools to those under study, what supports they considered most important and what were the causes which prevented them from achieving more success. On the other hand, they were asked about the most important supports students and families should get, factors 0 conditions that would make schools more successful and what probable future they could see. Finally, they were asked for their opinion on what typology of leaders they would demand in the future to manage efficiently urban schools such as the ones they managed.

The data collection relating to students, parents and teachers was executed through focus groups, which are well-founded as a technique to collect information. Authors as Krueger (1991), Ibáñez (2003), Alonso (1996) or Suárez Ortega (2005) have developed the theoretical framework in which it falls within. With focus groups we allude to sets of people (teachers, parents or students in this case) that meet with a specific purpose (to think about their school and its principals leadership), that have certain common characteristics (they are all members of a school community) and offer data (personal, from their own point of view), in a specific time and space (which we establish in the research), of a qualitative nature (material 
is produced after a discursive situation), in a guided conversation (characterized by non-directivity) by us (researchers), who act as moderators.

Relating to teachers, a focus group was carried out, and it contributed evidence of the following thematic clusters:

i) Their own perception of the school, identifying its key characteristics (strengths and challenges) concerning to students, the general school running, teachers and its conditions in the last five years. They were asked about their choice to continue working in the school or not, as well as the way they met daily challenges of their task and the supports they receive, if it is the case.

ii) Assessment of leadership and evolution within the school, contributing their vision of the principals' role, the kind of leadership they carry out, and also identifying the strategies used at different levels, both related to the school internal running as to its external renown.

iii) Focus group concluded with a paragraph of considerations about the essential qualities of principals in urban schools with challenges, about the supports and needs teachers, students and families have and, finally, about the elements to facilitate even more success in these schools.

Other focus groups were carried out with the students' families, with identical parameters than the one accomplished with teachers. Again, opinions were collected about their perception of the school, the existing leadership and the evolution along time, highlighting key aspects of their success and contributing opinions on the qualities they considered essential for principals in urban schools as well as on the conditions that would increase success in the school itself.

Collection of data concluded with those obtained through the focus groups with the students in each of the schools, who were asked questions abounding in the same sections described for parents and teachers, that is, their own perception of the school and the principals' leadership, their evolution and the factors that, from their point of view, would contribute to increase the school success.

\section{Analysis of data}

Data were analyzed through schemes and agreed guidelines, which have permitted to harmonize the task of the different teams and the contrast of the different contributions a posteriori, in the research group meetings.

The analysis techniques used have been mainly the open and axial codifications proposed by Strauss and Corbin (1990). This kind of codification means a close scrutiny of collected data during the research. It is a process which is initiated without restrictions, assigning conceptual labels to the incidents found in them. Afterwards, incidents and similar phenomenon are compared and contrasted, being assigned the same category to them. When these concepts are defined, the interrogation process opens and codification is initiated, which has a tentative character and, therefore, it is subject to changes, in the recurrent process of data contrast with the experience and knowledge that researchers introduce in the research process. On the other hand, axial codification enables an intense analysis around a codification category, identifying relations and data patterns. Through it, comparisons and questions become the focal point of the inductive/deductive analysis. Therefore, it focuses on specifying the categories, terms and conditions that made them arise, the specific context in which they are interwoven; and the action/interaction strategies 
that are carried out. These elements support a precise explanation of the phenomenon or categories and, later, the subcategories. The link of the subcategories with a category through the set of relations connects with the 'paradigm model' that Strauss and Corbin mention when they use the axial codification.

Operatively, we developed a sequence of three steps that respond to the following succession:

i) First, we held the transcription of the interviews made to principals, analyzing them and creating a categorical scheme of themes and topics according to the reached agreements. Later, the contents of the focus groups were transcribed, relating the new data to the categories emerged from the principals' contributions.

ii) Secondly, we created a matrix for each chapter, using the topics and headings resulting from the emptying of the contents of the interviews and focus groups, comparing the different points of view and the contributions of the participant groups.

iii) This phase of the research was concluded with a first report, according to the agreed scheme, that was materialized in a case study for each school that also included references to its social and economic context.

In September 2006, in Warsaw, we celebrated the first general meeting to coordinate the research group, in which we analyzed the thirty-six case studies and checked we had collected a very interesting material but excessively voluminous, overflowing the objective of configuring the materials for principals' training with a functional focus. In that meeting it was agreed to prepare a draft of experimental materials that should incorporate the reality of leadership, always from the perspective of viable strategies to train principals, which, in any case, had to be linked to experiences collected in the study cases, from which the most emerging facts and actions from the principals and school communities' contributions had to be extracted.

\section{Process of developing training materials}

When the contents of the study cases were emptied, we found out that the contributions were mainly related to nine topics: families, educational politics and administration, social communities, atmosphere and environment of learning, teachers, non-teaching staff supporting schools, students, management teams and some other general topics. Consequently, the research group agreed to elaborate schemes of the referred topics that would serve, after the appropriate analysis, to identify a number of elements for each one of them and to write the corresponding sector report. These elements were: the sort of school (Primary or Secondary), the problem or issue addressed, the context in which it was produced and described, the actions developed to solve it and boost the improvement, the analysis of the obtained results and, finally, what the principals and the educative community thought about those results.

This analytic process was developed during 2007 and the principals of the concerned schools participated actively. We carried out focus groups with them in the different countries which, in the Spanish case, concluded their case exploration highlighting the following topics:

- Compromise and involvement from the principal, parents, students and teachers to the school life.

- Extracurricular activities, as an element to encourage participation from all of them, and to ease their integration.

- Necessity of training seminars for teachers and parents. 
- A certain concept of education, as a means for change and social justice.

- Integration of immigrants.

- Building, all together, the school we want.

- Democratic practices at every school level.

- Collaborative work of students and teachers.

- Necessity of interdepartmental work.

- Inter-subject work and connection between the different curricula.

- Respect from students to teachers and vice versa, and mutual respect among students.

- Development of new methodologies (project-based learning, cooperative learning, etc.)

- Transparency, flexibility and perseverance in the management team's work.

- Difference, as an enriching element.

- Integration of people risking exclusion.

- Mentoring in pairs, in which expert students teach the school culture to the new ones.

With the different countries' contributions, the research group, met in Dublin in September 2007, produced two training materials drafts. One of them corresponded to Early Childhood and Primary schools and the other one to Secondary schools.

Again, the volume of the research group's contributions recommended selecting half of the schools for each educational level (Early Childhood and Primary on the one hand and Secondary on the other), so the two most representative ones in each country were chosen. With all of it two second materials drafts were elaborated, which included real, full of life experiences, exercises and tasks on them, as well as a selection of readings. They intended to offer professional development activities in order to support leadership strategies and practices at schools around seven topics: leaders' self-knowledge; socio-cultural diversity/inclusion; learning conditions at the classroom; sustainability; relationships/communication with the school staff; students' involvement in their own learning; justice and equity.

These materials have been designed to be used with both experienced principals and with those professionals wishing to become principals, as useful tools to: raise their consciousness about the most pressing questions and the most promising strategies; prioritize the principals' collective efforts in certain areas or countries (for example, providing an improvement agenda for the next two years); report the scientific community about relevant aspects (e. g., proposing to extend this study to other countries); demonstrate the diverse supporting roles political agents can play (for instance, justifying their financial support acting as mentors of new principals or improving the school services).

Together with this new version of the training materials a piloting process took place too, trough the focus group with principals and school leaders, in spring 2008. The sequence consisted in its introduction to each country group, to whom a copy was distributed so that, along four weeks, its members went through it and discussed about the materials on their own, contributing their own observations and amendments. Once this period was finished, the group met again, where opinions and assessments on the materials were expressed. In the Spanish group, the following ones should be highlighted:

a) The group considered that the materials' structure, that is, their modular format and the autonomy among their parts, was appropriate.

b) It also thought the seven topics around which the materials were organized were the most relevant ones on the whole. 
c) But it considered there was an excessive asymmetry among the sections within each topic, proposing that the extension of its different parts (proposals, tasks and readings) should be harmonized.

d) It believed necessary to emphasize the importance of some strategic elements for a successful management, these ones especially: to enjoy teachers' stability; to define the school educative project (citizenship and coexistence space); to develop welcome programs (in order to bring the schools closer to the families and make the students' arrival easier); to look for closer attitudes and agreements between the administrations and the schools and, finally, to redefine the concept of 'school success', relating it to the students' profiles and the answer to the needs derived from their diversity.

e) It showed a particular interest in two topics: socio-cultural diversity and justice and equity. To meet the problems related to them, it considered pertinent these strategies: to increase educative programs and resources; to provide a large offer of Vocational Training; to encourage teachers to adopt new methodologies (especially to make more flexible groups); to pay special attention to tutorial action and to get involved in conflicts solving; to improve the relationship between teachers and students; to make the access to principals easier for the whole school community; to increase the families' relationship, coordination and training (school for parents, mediation services, support to social aspects: regularization, health, accommodation...); to make teachers more professional (mainly through training at the work centre and learning teaching techniques to meet diversity); to improve coordination among teachers and promote new organizational solutions such as flexible groups, subjects organized in modules, etc.)

\section{Final drawing-up}

This research concluded collecting together the work done by all the national groups along 2008, what took place in the Nottingham final conference in August, where both researches and principals from the involved countries took part. After the appropriate debates and contributions, a definite selection of the materials was agreed, which are grouped around the following topics:

a) Diversity meeting and social/cultural inclusion.

b) Learning conditions at schools and classrooms.

c) Sustainability.

d) Teachers' professional development.

e) Challenges to involve students in their learning (participation, influence and change)

f) Justice and equity.

Each topic develops a training module which is organized in different parts. The first one starts with a short introduction to the module contents and characteristics. The second part specifies its aims, justifying it and explaining its possible uses. The third one offers a task proposal, which includes multiple exercises (to work individually or in collaborative/focus groups, to answer questionnaires and matrixes, etc.); most of them are based upon the participant principals' contributions, upon their quotations and mentions, upon the same sceneries offered by these studies and upon other ones that principals taking part in future training actions will be able to contribute. The module finishes with a selection of readings, in which texts, webs and some other supporting and deepening resources are proposed. 
They keep a modular structure because researchers and school communities consider it as the most appropriate and functional one. The seven modules of the project are structured according to the sequence explained in an above paragraph.

\section{CONCLUSIONS AND IMPLICATIONS}

The first conclusion to be reflected is that the research group has managed to implement the project successfully, since training materials have been elaborated with examples of key challenges and dilemmas as well as strategies used by principals to face up to them, integrating students from diverse socio-cultural contexts and raising their levels of achievement. The materials include real experiences, exercises and tasks, as well as a selection of meaningful readings, to reinforce their interest and facilitate the future principals' training.

On the other hand, a transnational research network has been activated, with a high productive capacity, which has managed to carry out its tasks with an important participation level and a high involvement from every participant. Besides, it has been the object of a positive valuation from an external agency: the Danish University of Education (Aarus University), by the team coordinated by Dr. Lejf Moos.

As for the diffusion of the research results, apart from specific actions in other participant countries, being limited to Spain, we shall point out that it has been the object of a wide treatment in the local and national media, with a certain periodicity along the three years. And, within the Portuguese-Spanish space the experience has been spread in the academic context, especially in the Successful Schools Conference which took place in Palma de Mallorca in April 2008, where a poster was submitted. A research article was also submitted to the world meeting of the Council on Education for Teaching (ICET 2008, Braga), in July 2008. Finally, a communication was submitted to the Educational Leadership Conference at Malta University in November 2008.

On the other hand, the research has motivated an intense reflective process from researchers and participant school leaders or communities, based upon the analysis of the educational politics and reforms as well as their effects on schools and leadership which, as Ferreira (2007) has pointed out, means to distinguish between two levels that correspond to different rationalities and produce diverse paradoxes related to autonomy. On the one hand, the legal context (politics level), which combine the decentralization and debureaucratization principles with the flexibility and autonomy discourse. On the other hand, the practice level (schools and teachers, at a local level) in which opportunities, challenges and limitations arise, in a context marked by a very centralized and bureaucratic tradition. In other words, politics orientated to decentralization and debureaucratization, together with their emphasis on valuation processes and results securing coexist with centralized practices, which underline the importance of structures and the value of formal procedures in the organizational culture. As a consequence, principals and teachers tend to worry much more about documents, about the application of legal rules and regulations, about the importance of formal meetings... rather than about the questions affecting the daily school life and teachers. As many authors hold, this situation drives to the appearing of tensions, ambiguities and dilemmas that must be taken into account when analyzing the challenges and strategies designed and applied at the school level (Knapp et al., 2003; Newman, King, \& Youngs, 2000). Nevertheless, despite the current tendencies towards uniformity, in the context of centralized and bureaucratized systems, schools and their leaders continue developing strategies and show specific qualities to face up to limitations and take advantage of opportunities. All of it highlights the importance of questions such as culture 
understanding, leadership and micropolitics, as well as interaction among them in different contexts, something authors like Dimmock and Walker (2005) or MacBeath (2006) have dealt with.

The developed case studies have emerged key questions related to the above mentioned perspectives, such as vision, passion, knowledge management, teachers and students' participation, motivation, ethics and morals in aims, leadership sharing, ability and pro-action. As for strategies, we have already underlined the high participation of teachers in questions related to the school management and organization, giving great importance to communication and exchange of information at both internal and external levels, to the need of assuring transparence in the students' assessment, as well as promoting collaborative work among teachers in order to guarantee the school curriculum coherence and to improve dynamics inside and outside the classrooms, through extracurricular activities, etc. Besides, the necessary refurbishing of the school installations together with the special attention to socio-cultural diversity and the students' learning process demand diverse curricula and more flexible ways to form groups of students.

Participants have identified some of the qualities successful leaders have, as their ability to promote participation and engagement among every school community member, to guarantee every decision is taken democratically and to introduce assessment of complex aspects (lesson planning coherence, students' assessment, welfare and healthy atmospheres at schools, etc.).

In short, this research provides evidences of how successful leaders mark differences, even within difficult circumstances, due rather to general conditions (the legal framework) or to specific school contexts. It also reinforce other researches about the role of leadership in the creation and continuity of those schools trying to become learning communities, as it has been described in Leithwood, Jantzi and Steinbach (1999), Fernández (2000), Barker (2001), OCDE (2005).

In Spain, the democratic management at schools started in the 1980s. Since then, they are directed by teams whose composition and functions have been modified along time, with some reforms relating to decentralization, autonomy and participation. Regulations have been adopted in order to avoid bureaucratization and to increase autonomy and self-management at schools. But in practice, these reforms were not always successful and many times they implied tensions, ambiguities and contradictions. Literature on educational leadership has often criticized hierarchical, centralized, bureaucratized approaches, opting more openly for perspectives of shared leadership based upon collaboration. Not always the legal framework and the leadership practices at Spanish schools have favored these approaches; what is more, in the last years a strengthen, effective leadership seem to have been imposed, answering to personal approaches rather than collaborative perspectives, orientated to accountability rather than participation and collegial school management. These thinking preconceptions affect increasingly diverse schools, whose complexity exceed a leadership of this kind and demands other ways of management through distributed approaches, which promote collaborative communities and learning/management networks, as the participant schools in this research have proved with their daily practices, achieving success for 'almost everyone', even within their complex contexts and despite the importance of the challenges they have ahead. 


\section{REFERENCES}

1. ALONSO LE. The discussion group in their practice: social memory, intertextuality and communicative action [in Spanish]. Revista Internacional de Sociología. 1996; 13:5-36. [Abstract] [Back to text]

2. BARKER B. Do leaders matter? Educational Review. 2001; 53(1):65-76. doi:10.1080/00131910120033664 [Back to text]

3. BASS BM. From transactional to transformational leadership: learning to share the vision. Organizational Dynamics. 1990; 18(3):19-31. [Back to text]

4. DIMMOCK C, WALKER A. Educational Leadership: culture and diversity. London: Sage; 2005. [Back to text]

5. ELMORE RF. Leadership as the practice of improvement. International Perspectives on School Leadership for Systemic Improvement, July 2006. Retrieved from http://www.oecd.org/dataoecd/2/8/37133264.pdf. [Back to text]

6. FERNÁNDEZ A. Leadership in an era of change. Breaking down the barriers of the culture of teaching. In C Day, A Fernandez, TE Hauge, J Moller (Eds). The life and work of teachers. International perspectives in changing times. London: Falmer Press; 2000, pp. 239-255. [Back to text]

7. FERREIRA FI. Transformation of the school and paradoxes of autonomy in Portugal [in French]. Revue Internationale d'Éducation de Sèvres. 2007; 46:45-54. [Back to text]

8. HARGREAVES A, FINK D. The seven principles of sustainable leadership. Educational Leadership. 2003; 61(7):1-12. [Full Text] [Back to text]

9. HOUSE RJ, SINGH JV. Organizational behaviour: some new directions for I/O psychology. Annual Review of Psychology. 1987; 38:669-718. [Abstract] [Back to text]

10. IBÁÑEZ J. Cómo se realiza una investigación mediante grupos de discusión. In M García Ferrando, J Ibáñez, $\mathrm{F}$ Alvira (Eds.). El análisis de la realidad social. Métodos y técnicas de investigación social. Madrid: Alianza; 2003, pp. 283-297. [Abstract] [Back to text]

11. KNAPP MS, COPLAND MA, FORD B, MARKHOLT A, MCLAUGHLIN MW, MILLIKEN M, TALBERT JE. Leading for learning: sourcebook; concepts and examples. Washington, DC: Center for the Study of Teaching and Policy; 2003. [Full Text] [Back to text]

12. KRUEGER RA. El grupo de discusión. Guía práctica para la investigación aplicada. Madrid: Pirámide; 1991. [Abstract] [Back to text]

13. LEITHWOOD KA, JANTZI D, STEINBACH R. Changing Leadership for Changing Times. Buckingham: Open University Press; 1999. [Back to text]

14. MACBEATH J. Stories of improvement: exploring and embracing diversity. Fort Lauderdale: International congress on school effectiveness and improvement; 2006. [Back to text]

15. NEWMANN F, KING MB, YOUNGS P. Professional development that addresses school capacity: lessons from urban elementary schools. American Journal of Education. 2000; 108(4):259-299. doi:10.1086/444249 [Back to text]

16. OECD. Formative assessment: improving learning in secondary classroom. Paris: OECD; 2005. [Abstract] [Back to text]

17. STRAUSS A, CORBIN J. Basics of qualitative research: grounded theory procedures and techniques. London: Sage; 1990. [Back to text]

18. SUÁREZ ORTEGA M. El grupo de discusión. Una herramienta para la investigación cualitativa. Barcelona: Laertes; 2005. [Back to text] 